\title{
Effect of Posture in Intraocular Pressure, Comparison between Normal and Glaucomatous Subjects.
}

Ram Shrestha ${ }^{1}$, Sagarika Patyal', Ramesh Bista1, Sagar Rajkarnikar ${ }^{1}$, Anu Gurung.

${ }^{1}$ Department of Ophthalmology, Shree Birendra Hospital, ${ }^{2}$ Department of ophthalmology, Armed Forces Medical College, Pune

\begin{abstract}
Introduction: Intraocular pressure (IOP) increases when changing from sitting to supine position with an average difference of 0.3 to $6.0 \mathrm{~mm}$ of $\mathrm{Hg}$. These postural changes of IOP have been found in normal persons, patients with ocular hypertension and normal tension glaucoma. The eye is relatively non-distensible, even small changes in the volume of aqueous humor may significantly change IOP. The increase in resistance in aqueous flow is thought to be the reason for higher IOP in supine compared to sitting position. The aim of this study was to analyze the effects of posture in intraocular pressure in normal and primary open angle glaucoma subjects. Methods: It was a prospective cross sectional study done in Armed Forces Medical College, Pune, between May, 2007 to May, 2009 with sample sized of 60 people (30 controls and 30 Primary open angle glaucoma). Patients underwent complete ocular examination. Two drops of Topical $4 \%$ lignocaine were instilled. IOP measurements were taken by Rebound tonometer in sitting and supine positions at 10 min and 30 min interval respectively. Results: Control group (40-76 yrs) and POAG group (40-78 yrs) were found to have a mean rise of IOP of 1.65 and $2 \mathrm{~mm}$ of $\mathrm{Hg}$ respectively from sitting to lying for 10min, and a mean rise of 2.52 and $5.36 \mathrm{~mm}$ of $\mathrm{Hg}$ respectively from sitting to lying for $30 \mathrm{~min}$. Conclusions: The rise in IOP due to change of posture from sitting to supine positions was significantly higher in glaucomatous patients.

Keywords: Intraocular pressure, Rebound tonometer, Ocular hypertension, Glaucoma
\end{abstract}

\section{INTRODUCTION}

Posture is one factor that has a longer effect on intraocular pressure (IOP). It increases when changing from sitting to supine position with an average difference of 0.3 to $6.0 \mathrm{~mm}$ of $\mathrm{Hg}^{1-3}$. This postural effect on IOP is greater in eyes with glaucoma ${ }^{4,5}$ and persists even after successful trabeculectomy $y^{6,7}$. These postural changes of IOP have been found in normal persons, ocular hypertensives and normal tension glaucomas ${ }^{4-6}$. Elevation of episcleral venous pressure on lying down, increases aqueous outflow resistance and causes rise in IOP.

Whole body head down tilt leads to a further increase in IOP, which correlates with degree of inversion ${ }^{8}$ is greater in glaucomatous eyes ${ }^{9,10}$. Glaucoma caused by raised episcleral venous pressure results in a direct effect on IOP. The ultimate IOP is influenced by the production and outflow of aqueous which is majorly balanced by episcleral venous pressure. More than $80 \%$ of aqueous outflow occurs through Schlemm's canal into episcleral veins ${ }^{11-15}$. The eye is relatively non-distensible, even small changes in the volume of aqueous may significantly change IOP.

The IOP postural response depends on arterial and venous vascular changes ${ }^{16-20}$. The aim of this study was to analyze the effects of posture in IOP in normal and primary open angle glaucoma.

\section{METHODS}

A prospective cross sectional study was done in Eye Outpatients Department, Armed Forces medical College, Pune where 30 cases of primary open angle glaucoma and 30 controls were taken. It was studied between May 2007 and May 2009.

The inclusion criteria were diagnosed cases of POAG, any sex, aged between 40 and $80 y$ rs with refractive error

\section{Correspondence:}

Maj. Dr. Ram Shrestha

Department of Ophthalmology, Shree Birendra Hospital.

Kathmandu, Nepal.

Email: ramshrestha5@gmail.com

Phone: +977-9851094260 
between $+3 \mathrm{D}$ and $-3 \mathrm{D}$ and IOP recorded $>21 \mathrm{mmHg}$ at least few occasions with Optic nerve head changes of glaucoma and Visual field damage.

The exclusion criteria were refractive error more than $3 \mathrm{D}$, subjects undergone any ocular surgery, ocular diseases like keratitis, uveitis, retinal detachment or corneal scar and patients on long term steroids (topical or oral). Importance of the test and description of the procedure was given to all patients and the informed consent was taken.

Patients underwent complete ocular examination consisting of best corrected visual acuity, slit lamp examination of anterior segment, optic nerve head examination, pachymetry, goniscopy. SITA Standard 24-2 Humphrey's automated perimetry was done.

Two drops of Topical $4 \%$ lignocaine were instilled in the eyes. IOP measurements were taken with the help of Rebound tonometer first in the sitting position and then in supine positions at 10 minutes and 30 minutes interval respectively. Topical antibiotic drop was put after each measurement.

Results were tabulated and statistical analysis was done. Descriptive and correlation significance was found out.

\section{RESULTS}

Total 60 cases were included in this study where 30 were primary open angle glaucoma (POAG) subjects and 30 were age matched controls.

Age range of POAG group was from 40 years to 78 years with a mean of 52.5 years. Age of Control group ranged from 40 years to 76 years with a mean of 49.6 years. The difference of mean age between these two groups was not significant $(\mathrm{p}=0.251)$.

In POAG group, the male were 13 and female 17 in number while in Control group 15 each respectively (Chi-square test, $\mathrm{p}=0.605$ ).

Table 1. difference in mean IOP measurements.

\begin{tabular}{|llll|}
\hline \multicolumn{1}{|c}{ Posture } & POAG group & Control group & P value \\
\hline Sitting ( Baseline) & 16.5 & 13.73 & $<0.001$ \\
$\begin{array}{l}\text { Lying down for } 10 \\
\text { min }\end{array}$ & 18.5 & 15.38 & $<0.001$ \\
$\begin{array}{l}\text { Lying down for } \\
\text { 30min }\end{array}$ & 21.86 & 16.25 & $<0.001$ \\
\hline
\end{tabular}

The mean IOP measurement in POAG group was significantly higher in every posture in compare to Control group.

Table 2. Rise in IOP

\begin{tabular}{|lccc|}
\hline Rise of mean IOP & $\begin{array}{c}\text { Control } \\
\text { Group }\end{array}$ & $\begin{array}{c}\text { POAG } \\
\text { Group }\end{array}$ & P value \\
\hline $\begin{array}{l}\text { From sitting to lying } \\
\text { down for 10 min }\end{array}$ & 1.65 & 2.0 & $<0.001$ \\
\hline $\begin{array}{l}\text { From sitting to lying } \\
\text { down for 30 min }\end{array}$ & $\mathbf{2 . 5 2}$ & $\mathbf{5 . 3 6}$ & $<\mathbf{0 . 0 0 1}$ \\
\hline
\end{tabular}

\section{DISCUSSION}

Body position is important factor in determining the intraocular pressure because the eye is relatively non distensible and even small changes in volume significantly change IOP. Moreover, uveal engorgement may also increase the perfusion of the ciliary body, increase in production of aqueous thereby increasing IOP. Weber \& Price et al claimed that with posture, there is an increase in diastolic arterial pressure resulting in dilatation \& increased perfusion of the ciliary processes causing increased formation of aqueous.

In a study conducted by $\mathrm{J}$ Parsley et $\mathrm{al}^{8}$, forty-six eyes with POAG and 24 eyes which had previously undergone trabeculectomy for POAG were studied and the postural response of the intraocular pressure was compared to that of 70 normal eyes. In all three groups, the greatest rise in IOP occurred when the subject changed from the sitting to the lying position. In a study by A S Kothari et al, IOP was higher in hypertensive patients and postural response of IOP was significantly higher in these patients as compared to controls.

Our findings are similar to both these studies. IOP has been reported to be higher with the patient supine than when sitting. While awake, individuals usually are either standing or sitting and one third or one quarter of the day is spent in supine position, asleep. When sitting or standing, the eye is $30 \mathrm{~cm}$ higher than the heart. However, when the patient is supine, the eye and the heart are at almost the same level. This gap in height is thought to affect the episcleral venous blood flow. Orbital venous pressure increases quickly, depending on posture because of numerous interconnections between the orbital drainage routes and the lack of venous valves in the orbit. This causes an increase in the resistance to aqueous outflow. 
A decrease in mean arterial pressure (MAP) or an increase in IOP can decrease ocular perfusion. Systolic blood pressure (BP) and IOP decrease significantly from supine to sitting position where as diastolic BP increases significantly. Changes in IOP also occur with head down position and are believed to be due to either increase in episcleral venous pressure, increased aqueous production with increased ciliary body blood flow, choroidal vascular engorgement or a barorecepter type reflex phenomenon.

Phyburg and Weinreb found that IOP dramatically increased to more than $30 \mathrm{~mm}$ of $\mathrm{Hg}$ and retinal arterioles markedly constricted with the head down vertical position. Values in all patients with autonomic dysfunctions were higher in the supine than in the standing position.

In the Barbados Eye Studies, Sun Yuh Wu et al have stated that IOP changes were positively associated with male sex, hypertension, diabetes, higher systolic and diastolic blood pressure. A $10 \mathrm{~mm} \mathrm{Hg}$ increase in systolic or diastolic blood pressure was associated with an approximately 0.2 $\mathrm{mm} \mathrm{Hg}$ or $0.4 \mathrm{~mm} \mathrm{Hg}$ increase in IOP. Part of the nocturnal increase in IOP has been attributed to a change from sitting to supine position with sleep. Altered retrobulbar hemodynamics have been found in glaucoma patients compared to controls by stimulating nocturnal postural change from sitting to supine position.

\section{CONCLUSIONS}

There is rise in the intraocular pressure due to change of posture from sitting to supine positions, seen more in glaucomatous patients.

\section{REFERENCES}

1. David R, Zangwill L, Stone D, et al. Epidemiology of intraocular pressure in a population screened for glaucoma. Br. J. Ophthalmol. 1987;71(10):766-71.

2. Leske MC. The epidemiology of open-angle glaucoma; a review. Am J Epidemiol. 1983;118:116-9.
3. Spierer A. Eisentein Z. The role of increased intraocular pressure on up gaze in the assessment of Grave's ophthalmopathy. Ophthalmology. 1991;98(10):1491-4.

4. Anderson DR. Grant MW. The influence of position on intraocular pressure. Invest Ophthalmol Vis Sci. 1973;12:204-12.

5. Yamabayashi S. Aguilar Rn. Hosoda M. et al. Positional change in intraocular and blood pressure in ocular hypertension and tension glaucoma. Br J Ophthalmol. 1991;75(11):652-5.

6. Parsley J. Powell RG. Keithley SJ et al. Postural response of intraocular pressure in chronic open angle glaucoma following trabeculectomy. Br J Ophthalmol. 1987;71:494-6.

7. Wilensky JT, Zeimer RC, Gieser DK, Kaplan BH. The effects of glaucoma filtering surgery on the variability of diurnal intraocular pressure. Trans Am Ophthalmol Soc. 1994;92:337-383.

8. Linder BJ. Trick GL. Wolf ML. Altering body position affects intraocular pressure and visual function. Invest Ophthalmol Vis Sci. 1988;29(10):14927.

9. Weinreb RN, Cook J, Friberg TR: Effect of inverted body position on intraocular pressure. Am J Ophthalmol. 1984, 98(6):784-7.

10. Chiquet C. Custaud M-A, Le troan A-et al. Changes in intraocular pressure during prolonged (7-day) head-down tilt bedrest. J Glaucoma 2003;12(3):204-8.

11. Friberg TR, Sanborn G, Weinreb RN. Intraocular and episcleral venous pressure increase during inverted posture. Am JOphthalmol. 1987;103:5236.

12. Townsend DJ, Brubaker FJ. Immediate effect of epinephrine on aqueous formation in the normal human eyes measured by fluorophotometry. Invest Ophthalmol Vis sci. 1980;19(3):256-66.

13. Gabelt BT, Kaufman PL. Aqueous humor hydrodynamics. In: Kaufman PL, Alm A, eds. Adler's physiology of the eye. St. Louis: Mosby; 2003:p237.

14. Fine BS. Structure of the trabecular meshwork and the canal of Schelemm. Trans Am Acad Ophthalmol Otolaryngol. 1966;70(5):777-90.

15. Tripathy RC. Mechanism of the aqueous outflow across the trabecular wall of schlemm's canals. Exp Eye Res 1971;11(1):116-21.

16. Emi K, Pederson JE, Toris CB. Hydrostatic pressure of the suprachoroidal space. Invest Ophthalmol Vis Sci. 1983;24(6):725-6.

17. Macri FJ: Interdependence of venous and eye pressure. Arch ophthalmol. 1961;65:442-49.

18. Moses RA. Grodzki WJ Jr. Choroid tension and facility of aqueous flow. Ophthalmol Vis Sci. 1977;16(11):101-62.

19. Bill A. Blood Circulation and fluid dynamics in the eye. Physsio Rev. 1975;55(3):383-417.

20. Blondeau P, Tetrault JP, Papamarkakis C. Diurnal Variation of episcleral venous pressure in healthy patients: a pilot study. J Glaucoma 2001;10(1):18-24. 